\title{
Assessing the Impact of Projected Climate Change on Zoo Visitation in Toronto (Canada)
}

\author{
Micah J. Hewer ${ }^{1} \&$ William A. Gough ${ }^{2}$ \\ ${ }^{1}$ Department of Geography, University of Toronto, Toronto, Ontario, Canada \\ ${ }^{2}$ Department of Physical and Environmental Sciences, University of Toronto Scarborough, Scarborough, \\ Ontario, Canada \\ Correspondance: Micah Hewer, Department of Geography, University of Toronto, Toronto, ON, M5S 3G3,
} Canada. Tel: 1289-880-8502. E-mail: micah.hewer@mail.utoronto.ca

Received: February 4, 2016

Accepted: February 21, 2016

Online Published: March 22, 2016

doi:10.5539/jgg.v8n2p30

URL: http://dx.doi.org/10.5539/jgg.v8n2p30

This research did not receive any external funding

\begin{abstract}
Weather and climate have been widely recognised as having an important influence on tourism and recreational activities. However, the nature of these relationships varies depending on the type, timing and location of these activities. Climate change is expected to have considerable and diverse impacts on recreation and tourism. Nonetheless, the potential impact of climate change on zoo visitation has yet to be assessed in a scientific manner. This case study begins by establishing the baseline conditions and statistical relationship between weather and zoo visitation in Toronto, Canada. Regression analysis, relying on historical weather and visitation data, measured at the daily time scale, formed the basis for this analysis. Climate change projections relied on output produced by Global Climate Models (GCMs) for the Intergovernmental Panel on Climate Change's 2013 Fifth Assessment Report, ranked and selected using the herein defined Selective Ensemble Approach. This seasonal GCM output was then used to inform daily, local, climate change scenarios, generated using Statistical Down-Scaling Model Version 5.2. A series of seasonal models were then used to assess the impact of projected climate change on zoo visitation. While accounting for the negative effects of precipitation and extreme heat, the models suggested that annual visitation to the zoo will likely increase over the course of the $21^{\text {st }}$ century due to projected climate change: from $+8 \%$ in the 2020 s to $+18 \%$ by the 2080 s, for the least change scenario; and from $+8 \%$ in the 2020 s to $+34 \%$ in the 2080 s, for the greatest change scenario. The majority of the positive impact of projected climate change on zoo visitation in Toronto will likely occur in the shoulder season (spring and fall); with only moderate increases in the off season (winter) and potentially negative impacts associated with the peak season (summer), especially if warming exceeds $3.5^{\circ} \mathrm{C}$.
\end{abstract}

Keywords: weather sensitivity, climate change impacts, tourism and recreation, zoo visitation, tourism seasonality, tourist behaviour

\section{Study Context}

International tourism accounts for 30\% of the world's exports of services and $6 \%$ of world's total exports, according to the United Nations World Tourism Organization (UNWTO, 2015). As an export category, it ranks fourth worldwide, after fuels, chemicals and food, but notably ahead of automotive products (UNWTO, 2015). Furthermore, compared to fuels, earnings from international tourism benefit a larger number of exporters and the sector also tends to generate more employment (UNWTO, 2015). In 2014, 1.3 billion people travelled internationally, up $4.4 \%$ from 2013, marking a fifth year of consecutive growth since the global economic crisis in 2009 (UNWTO, 2015).

According to the Canadian Tourism Commission (CTC, 2015), Canada's tourism industry is one of the country's fundamental economic drivers and is the country's number one service export. Total overnight international visitors to Canada increased to 17.1 million in 2014, up 3.2\% from 2013 (CTC, 2015). In 2014, the Canadian tourism industry supported nearly 627,000 jobs, being comprised of over 170,000 tourism business establishments (CTC, 2015).

Based on the most recent figures released by the Ontario Ministry of Tourism, Culture and Sport (OMTCS, 
2015), Ontario received $\$ 28.1$ billion in total tourism receipts in 2012; representing $4.2 \%$ of provincial GDP that year. In the same year, tourism in Ontario created 359,000 jobs, representing 5.2\% of provincial employment in 2012 (OMTCS, 2015). Tourism in Ontario also generated $\$ 4.9$ billion in tax revenue for 2012 , representing $4.2 \%$ of provincial revenues that year (OMTCS, 2015).

In 2013, 40 million people visited the greater Toronto region (13.7 million overnight visitors), generating visitor expenditures of approximately $\$ 6.5$ billion (Tourism Toronto, 2014). The Toronto Zoo is marketed as a world-class zoo and is a highly recognised and promoted tourism attraction in the region (Tourism Toronto, 2014). The Toronto Zoo is therefore an important element of the tourism industry in this region, recording 1.43 million visitors in 2013 (Toronto Zoo, 2014). The zoo is a municipally owned and operated organization with a mission to protect wildlife populations and their habitats by facilitating conservation programs and offering wildlife education opportunities (Toronto Zoo, 2014). In 2013, the Toronto Zoo (2014) declared operating expenses of nearly $\$ 53$ million. Approximately $73 \%$ of the zoo's operating expenses were covered by admission fees, membership sales and other visitor services; the remaining expenses were funded by the City of Toronto (Toronto Zoo, 2014). Since visitor revenues are essential for funding conservation and education programmes at the zoo, it is vital for operations management and city planners to understand external factors that may influence visitation trends.

Weather and climate are two of the critical elements for the natural resource-base of recreation, and are exploited by the tourism industry (de Freitas, 2003). According to Butler (1998), climate and weather also determine the length and quality of certain recreational seasons, by controlling when certain activities are available for participation. Since tourism and recreation are voluntary activities undertaken for personal satisfaction and pleasure (Yukic, 1970); it was argued by de Freitas (2003) that participation will only occur if the participant perceives conditions to be suitable. Weather and climate directly affect tourist satisfaction (Williams et al. 1997); satisfaction in turn affects participation (Butler, 1998), which can be considered a measure of demand for a climatic resource (de Freitas, 2003). The relationship between satisfaction and participation is therefore a reflection of climate and weather related decision-making among tourists (de Freitas, 2014).

Climate was once considered one of the more stable properties of tourism destinations (Abegg et al. 1997). However, this position has been recently abandoned given the increasing evidence of global climate change (Moreno \& Amelung, 2009). According to the Intergovernmental Panel on Climate Change (IPCC, 2013), warming of the climate system is unequivocal, and since the 1950s, many of the observed changes are unprecedented over decades to millennia. The earth's atmosphere and oceans have warmed, the amounts of snow and ice have diminished, sea level has risen, and the concentrations of greenhouse gases (GHGs) have increased (IPCC, 2013). Each of the last three decades has been successively warmer at the Earth's surface than any preceding decade since 1850 (IPCC, 2013). In the Northern Hemisphere, 1983-2012 was likely the warmest 30 -year period of the last 1400 years (IPCC, 2013). By the end of the 21st century, a warming of between 1.7 to $4.8^{\circ} \mathrm{C}$ is expected for global annual mean surface air temperatures (IPCC, 2013). Continued emissions of GHGs will cause further warming and changes in all components of the climate system (IPCC, 2013). Most aspects of climate change will persist for many centuries even if emissions of $\mathrm{CO}_{2}$ are stopped (IPCC, 2013). Numerous assessments have suggested that climate change is likely to affect tourist destination choice, activity selection, seasonality and tourism demand; from which multiple climate change and tourism literature reviews have recently emerged (Scott et al. 2012; Becken, 2013; Kajan \& Saarinen, 2013; Pang et al. 2013; Rossello-Nadal, 2014; Njoroge, 2015).

However, the precise relationship between weather and recreation is not universal for all forms of tourism, as certain activities have different climatic requirements (Morgan et al. 2000; Scott et al. 2008; Rutty \& Scott, 2010; Hewer et al. 2014). For this reason, climate change impact assessments that focus on international tourism arrivals without distinguishing between the various tourism activities involved in certain national tourism economies are considered conceptually unsound (de Freitas et al. 2008; Scott et al. 2008; Scott et al. 2012). It is therefore essential to examine each tourism segment individually, in order to effectively determine its relative weather sensitivity (de Freitas et al. 2008); from which more informed climate change impact assessments can be conducted.

In a Canadian context, a number of climate change impact assessments have been conducted on different tourism and recreation activities that were perceived to be vital to the national tourism economy and vulnerable to climatic change and variability. Climate change impact assessments in a Canadian context have focused on the ski industry (Scott et al. 2002, 2003, 2006, 2007a); parks and protected areas (Jones \& Scott, 2006a, 2006b; Scott et al. 2007b; the golf industry (Scott \& Jones, 2006, 2007); as well as general tourism activities such as sightseeing and shopping (Scott et al. 2004). Overall, climate change is expected to have a significant impact on 
tourism seasonality and tourist visitation in Canada. In regard to warm-weather recreational activities, climate change is expected to cause conditions in Canada to become more suitable for tourism. Inversely, climate change is expected to have negative impacts on winter-season recreational activities, especially those dependent on snow or ice as the main climatic resource. Although our understanding of climate change impacts and tourism in Canada has improved substantially, especially since the turn of the century, there is still a great need for further research in this field. A number of important tourism activities and attractions have yet to be assessed in relation to their respective weather sensitivity or the subsequent impacts of projected climate change. Climate change is very likely to present a number of different opportunities and threats for the tourism industry in Canada, much of which has yet to be explored in a formal scientific manner. As a result, the on-going assessment of the weather sensitivity and potential climate change impacts associated with tourism activities in Canada is an important area of future research, in order to foster more informed climate change adaptation strategies across the industry.

There has been only limited research conducted in regard to the relationship between zoos and aquariums with climate and climatic change. Junhold and Oberwemmer (2011) summarised the way climate change might directly impact zoos and aquariums in regard to their conservation planning. Furthermore, Pearce-Kelly et al. (2013) discussed the increasing demand on zoos and aquariums due to the threat of projected climate change on global biodiversity; illustrating the likelihood that more species will require ex-situ conservation efforts due to harmful climate and climate-induced environmental change. The significant climate change-related research potential of aquariums and zoos has been highlighted by Barbosa (2009). Aylen et al (2014) used multivariate regression analysis to determine the statistical relationship between climate and weather with average monthly and total daily visitation to a particular zoo in Manchester, England. The study reported that zoo attendance is sensitive to weather and climate variability, but concluded that projected climate change is unlikely to have a major impact on zoo visitation in that region (Aylen et al. 2014). However, no research to date has formally assessed the impact of projected climate change on zoo visitation numbers, patterns of seasonality, or the implications for revenue generation and management responses.

\section{Establishing the Baseline}

The first step in a formal climate change impact assessment is to understand the baseline conditions relating to the climatic variables of interest (temperature and precipitation, in this case) as well as for the exposure unit (zoo visitation). A climatic baseline, or climate normal, is generally understood as a period of at least 30 years (IPCC, 2007). Taking the most recent 30 year period, the baseline period for this study is therefore 1981 to 2010 . Climate data for this period was retrieved from the closest Environment Canada meteorological station in proximity to the Toronto Zoo with the required data for the variables of interest (Richmond Hill weather station, in this case). Data for the exposure unit was obtained directly from the Toronto Zoo. However, visitation data was not available for the entire baseline period (1981-2010); but rather, only for the period from 1999-2013. The climatic and visitation data retrieved for this study were all measured at the daily time scale, which enables a more accurate and precise investigation of the relationship between weather and visitation, as well as the prediction of future visitation under a changed climate, since visitors respond to the current and expected atmospheric conditions on a given day (de Freitas, 2003). Monthly and annual averages are not relative to actual visitor decision-making (de Freitas, 2003, de Freitas et al. 2008); therefore, using these course aggregate measures to model the relationship between climate and visitation and then predict future patterns of tourist behaviour (Jones and Scott 2006a, 2006b; Loomis and Richardson, 2006; Scott et al. 2007b; Fisichelli et al. 2015), could be problematic.

Nonetheless, in order to understand the current trends in these variables of interest over time, it was necessary to reduce the daily weather and visitation data to its annual aggregate form (Figure 1). Fig 1 shows the change in average annual temperature (both minimum and maximum, ${ }^{\circ} \mathrm{C}$ ), as well as total annual precipitation $(\mathrm{mm})$, over the baseline period from 1981 to 2010 . Figure 1 also records the equation for the slope of the linear trend line and the results from a linear regression analysis, to illustrate the statistical strength of the relationship. 

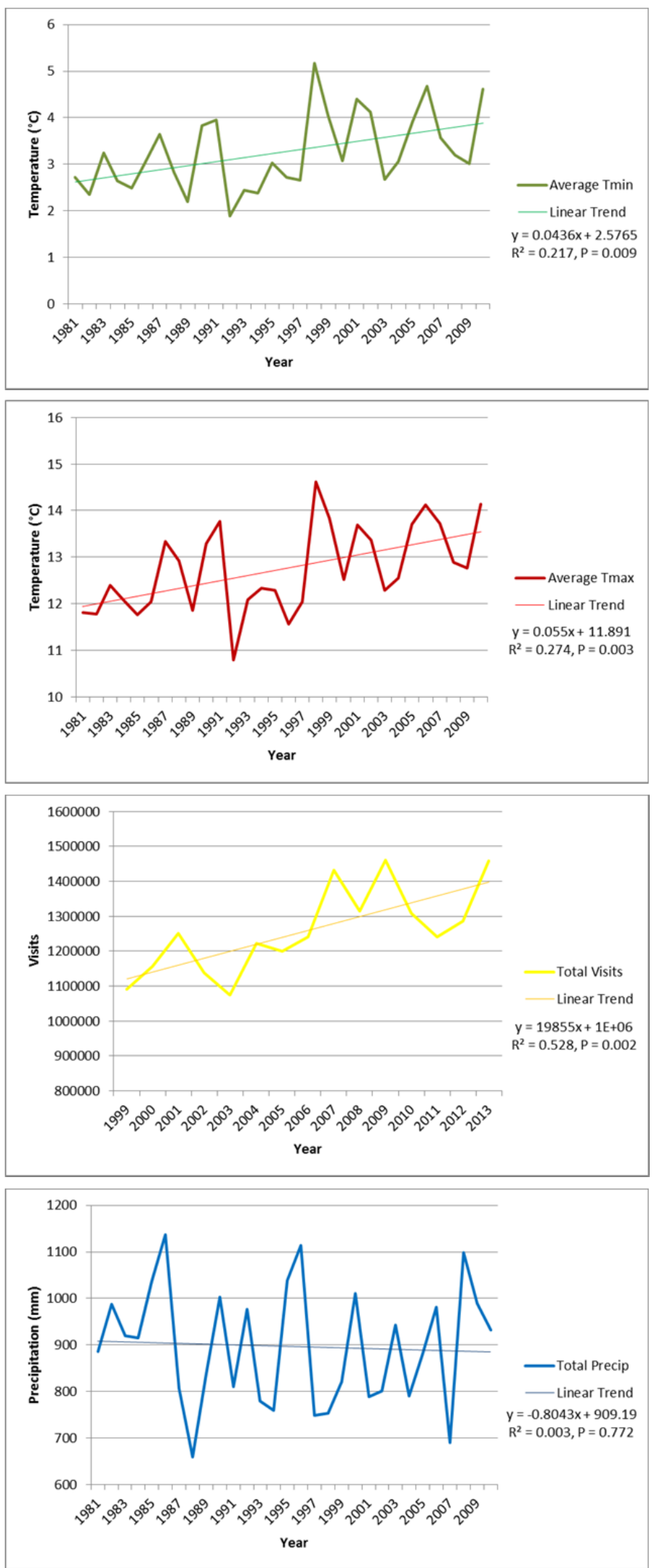

Figure 1. Linear Trends in Baseline Climate Conditions for Richmond Hill from 1981-2010 and Visitation for the

Toronto Zoo from 1999-2013 (Top left: annual average for daily maximum temperatures; top right: annual average for daily minimum temperatures; bottom left: annual sum for total daily precipitation; and bottom right: annual sum for total daily visits) 
From this preliminary analysis, it is evident that both measures of temperature have been increasing over time within the study region. Average annual maximum temperatures (Tmax) have been increasing at a rate of $0.06{ }^{\circ} \mathrm{C}$ per year, over the course of the baseline period, this trend was found to be statistically significant at the $95 \%$ confidence interval $\left(\mathrm{R}^{2}=0.274, \mathrm{P}=0.003\right)$. Average annual minimum temperatures $(\mathrm{Tmin})$ also displayed a positive linear trend, but to a lesser degree, increasing by $0.04{ }^{\circ} \mathrm{C}$ per year, yet still being statistically significant $\left(R^{2}=0217, P=0.009\right)$. Total annual precipitation, was most variable from year to year, and although there was some suggestion of a negative linear trend (decreasing by $0.8 \mathrm{~mm}$ per year), the relationship between time and precipitation was not found to be statistically significant for the study region $\left(R^{2}=0.003, P=0.772\right)$. Even though the data set for total annual zoo visitation had the smallest sample size since there were fewer years of available data (15 years rather than 30$)$, it still recorded the strongest statistical relationship with time $\left(\mathrm{R}^{2}=\right.$ $0.528, \mathrm{P}=0.002$ ). According to the slope of the linear trend line, total annual zoo visitation has been increasing at the rate of nearly 20,000 visitors each year, over the course of the baseline period from 1999 to 2013.

What we learn from this preliminary analysis is that temperatures have already been increasing within the study region. Some of this may be attributable to global climate change; however, a greater percentage in likely the effect of the Urban Heat Island (UHI) that characterises this region (Gough \& Rosanov, 2001; Mohsin \& Gough, 2012). Nonetheless, it is reasonable to conclude that temperatures will continue to increase in this region due to the combined effects of global climate change and the UHI. Therefore, even without the use of sophisticated Global Climate Models (GCMs), zoo managers can reasonably anticipate a continued warming trend, which if the current trend continues, could result in annual average temperatures increasing by $4.5^{\circ} \mathrm{C}$ come the end of the 21 st century. There was no observable trend in precipitation over the baseline period for the study region; therefore, uncertainty remains concerning the role of precipitation under a changed climate. Although there were only 15 years of data to analyse, zoo visitation showed the strongest positive trend, which suggests that visitation is likely to continue to increase, regardless of future climate change impacts. This gradual increase in zoo visitation is most likely due to population growth in the region, accompanied by subsequent zoo expansion. At the current rate of increase, average annual zoo visitation is on track to nearly triple by the end of the $21^{\text {st }}$ century (increasing from just over one million annual visitors to nearly three million by the year 2100). However, maintaining this rate of increase is conceptually unreasonable, as at some point in the future population growth in the region will likely level off and more importantly, the physical infrastructure of the zoo and its ability to further expand will reach their limits as well, at which point annual visitation will likely plateau.

Although monthly averages for weather and visitation are not appropriate measures for use in predictive models designed to project future behaviour, they still do have application when trying to understand the natural and institutional seasonality associated with both climate and participation in a given tourism and/or recreation context. In order to visually present and compare the patterns of seasonality associated with the two climate variables (temperature and precipitation) as well as the exposure unit (zoo visitation), the raw data was aggregated into monthly averages for the period from 1999-2013 and then the standardised scores were equated for each variable. Standardised scores, or $Z$ scores, for each variable were determined by subtracting the average of all twelve months from the average for each month, then dividing by the standard deviation of the 12 monthly averages. The resulting $Z$ scores from each variable, for each month, are presented in Figure 2.

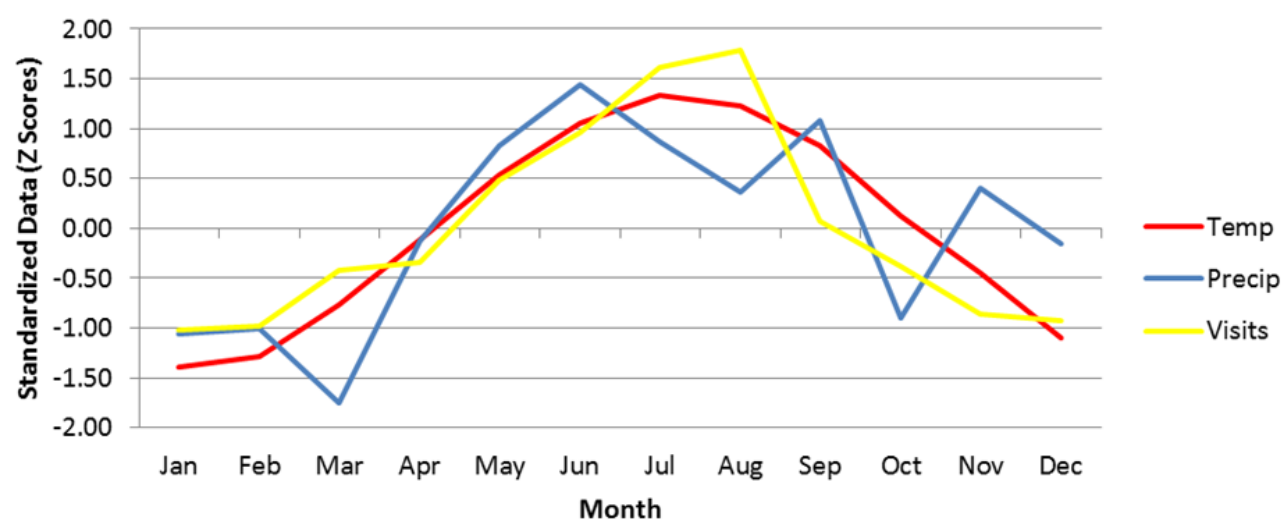

Figure 2. Seasonality of Temperature, Precipitation and Zoo Visitation (Monthly averages for temperature, precipitation and zoo visitation from 1999 to 2013 computed into standardized data ( $Z$ scores) the plotted, in order to compare variables recorded in different units of measurement) 
What becomes apparent from this illustration is that although temperature increases gradually from the winter low, continuing to rise through the spring and then peaks in the summer before beginning its decline in the fall; visitation does not mimic this pattern precisely. It is apparent that visitation seems to follow the pattern of temperature, in general, but there are some irregularities. Visitation is somewhat level and non-responsive to changes in temperature from November to February, then visitation begin to increase rapidly in March and follows the increases in temperature until the summer months of July and August when visitation in even higher than what can be expected due to the summer increase in temperature alone. Finally, temperatures gradually decline from the summer, through the fall and into the winter but visitation's decline is much more abrupt and drops sharply once August ends.

The pattern for precipitation is much harder to follow and seemingly acts counter to that of temperature and visitation, with the wettest months also being quite warm with high levels of visitation. Since the relationship between temperature and visitation does not appear to be constant across the different seasons, it makes intuitive sense that it may be necessary to model each season separately. For example, since temperatures are quite cold, on average, from November to February, day to day temperature variability is unlikely to have much of an effect on visitation patterns. However, once temperatures rise into a more comfortable range, such as from March to June, as well as September and October, it is more likely that visitation will be more sensitive to temperature variability. Finally, it is apparent that something other than temperature is driving the exceptionally high levels of visitation in July and August. The most likely explanation is the fact that many schools are closed during these months and parents are more likely to take time off work and participate in tourism and recreation activities with their children during this time; therefore these months should be modelled separately as well.

Given that fact that the data for this study was measured at the daily time scale and that the predictive models are designed to project future visitation based on changes in temperature and precipitation at the same scale, it is important to understand the day-to-day variability of the exposure unit. Certain social features that will likely remain constant in the future have considerable influence on the day-to-day variability of zoo visitation and therefore will be useful inclusions when creating predictive weather-visitation models. For example, weekdays (Monday to Friday) are associated with considerably lower levels of visitation than weekends (Saturday and Sunday). Furthermore, certain months contain institutional holidays that result in visitation levels which are even higher than those experienced on weekends during that month (Figure 3). All months except June and November have some form of holiday that is characterised by higher than average visitation. Most of these holidays result in what is referred to as a "long weekend" and the increased visitation usually occurs on either the Friday or Monday, depending on the timing of the holiday. Two exceptions are the months of March and December, in which there is a full week when holiday like visitation occurs associated with times that many schools in the region go on breaks.

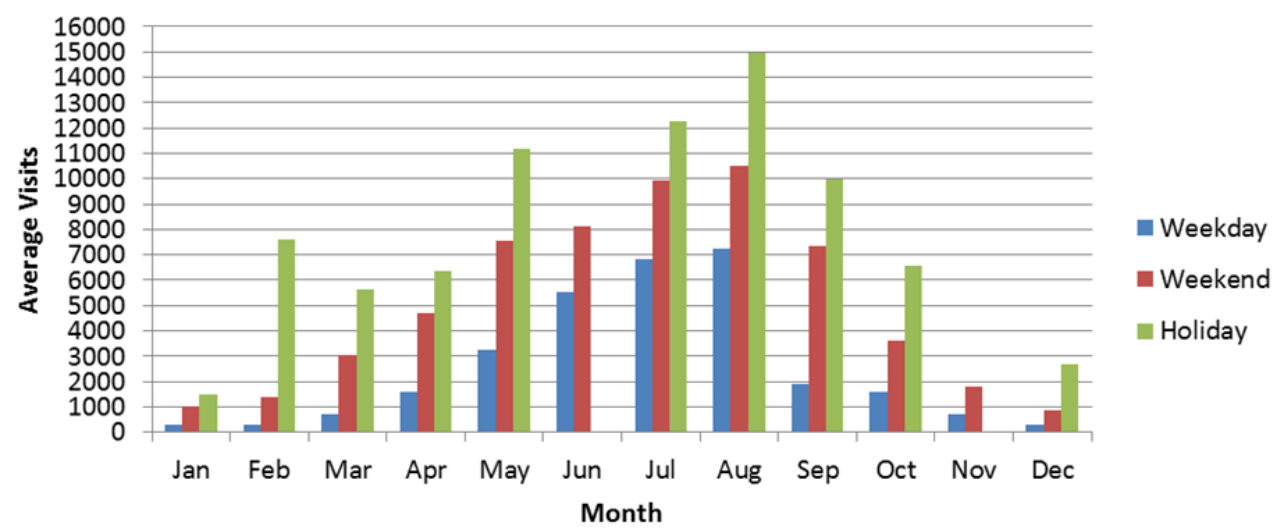

Figure 3. Day-to-Day Variability associated with Zoo Visitation due to Institutional Factors (Average visitation recorded for weekdays, weekends and holidays within each month)

\section{Creating Predictive Weather-Visitation Models}

Based on the preliminary baseline analyses, informed construction of predictive weather-visitation models was possible. Since the relationship between weather and visitation seemed to vary across seasons, three different models were created. An off-season model was created for the months from November to February, a shoulder season model for March to June, along with September and October; then finally, a peak season model was 
created for July and August. In addition to the selected climatic variables, a number of social variables were also included. A yearly rank variable was created and included to control for the observed positive linear trend in total annual zoo visitation, which serves as a proxy for population growth and zoo expansion. Binary variables were created and included to control for the effect of weekends and holidays on the day-to-day variability of zoo visitation. In an effort to normalise the data and meet the assumptions of regression analysis, the natural logarithm transformation was employed of zoo visitation data for both the off and shoulder season models. Daily precipitation data was transformed into a daily precipitation scale: $0 \mathrm{~mm}$ (no rain); 0 to $2 \mathrm{~mm}$ (trace rain); 2 to 5 $\mathrm{mm}$ (light rain) 5 to $10 \mathrm{~mm}$ (rain); 10 to $20 \mathrm{~mm}$ (heavy rain); and more than $20 \mathrm{~mm}$ (very heavy rain). Finally, a binary temperature threshold variable was included in the shoulder season model since it was hypothesised that at some critical point the positive linear trend between temperature and visitation would reach a break point and conditions would become too hot, causing visitation to decline. After testing a series of temperature thresholds within the model, it was determined that the binary variable which triggered when temperatures exceeded $26{ }^{\circ} \mathrm{C}$ had the strongest influence. Table 1 records the summary statistics for each of the three seasonal weather-visitation models.

Table 1. Seasonal weather-visitation predictive regression models

\begin{tabular}{|c|c|c|c|c|c|}
\hline Predictor Variable & Beta & Part. Corr. & $\mathrm{B}$ & $\mathrm{t}$ & $\mathrm{P}$ \\
\hline \multicolumn{6}{|c|}{ OFF SEASON MODEL $\left(\mathrm{R}^{2}=0.597, \mathrm{~F}=525.15, \mathrm{P}<0.001, \mathrm{SEE}=0.654, \mathrm{~N}=1777, \mathrm{~d}=1.46\right)$} \\
\hline Intercept (LN of Visits) & & & 5.553 & 151.404 & $<0.001$ \\
\hline Year Rank (1-15) & 0.099 & 0.099 & 0.024 & 6.545 & $<0.001$ \\
\hline Weekend Binary $(0,1)$ & 0.437 & 0.437 & 0.995 & 28.955 & $<0.001$ \\
\hline Holiday Binary $(0,1)$ & 0.395 & 0.393 & 1.691 & 26.079 & $<0.001$ \\
\hline Maximum Temperature $\left({ }^{\circ} \mathrm{C}\right)$ & 0.502 & 0.499 & 0.081 & 33.102 & $<0.001$ \\
\hline Precipitation Scale (0-5) & -0.206 & -0.206 & -0.168 & -13.633 & $<0.001$ \\
\hline \multicolumn{6}{|c|}{ SHOULDER SEASON MODEL $\left(R^{2}=0.631, F=768.06, P<0.001, S E E=0.623, N=2698, d=1.20\right)$} \\
\hline Intercept (LN of Visits) & & & 6.141 & 162.929 & $<0.001$ \\
\hline Year Rank (1-15) & 0.042 & 0.042 & 0.010 & 3.55 & $<0.001$ \\
\hline Weekend Binary $(0,1)$ & 0.443 & 0.438 & 1.005 & 37.458 & $<0.001$ \\
\hline Holiday Binary & 0.343 & 0.335 & 1.665 & 28.617 & $<0.001$ \\
\hline Maximum $\mathrm{T}$ & 0.680 & 0.559 & 0.082 & 47.751 & $<0.001$ \\
\hline Threshold $($ Tmax $>2$ & -0.121 & -0.101 & -0.379 & -8.596 & $<0.001$ \\
\hline Precipitation Scale $(0-5)$ & -0.174 & -0.174 & -0.130 & -14.825 & $<0.001$ \\
\hline \multicolumn{6}{|c|}{ PEAK SEASON MODEL $\left(\mathrm{R}^{2}=0.567, \mathrm{~F}=241.33, \mathrm{P}<0.001, \mathrm{SEE}=2077.3, \mathrm{~N}=926, \mathrm{~d}=1.81\right)$} \\
\hline Intercept (Visits) & & & 12259.01 & 34.222 & $<0.001$ \\
\hline Year Rank (1-15) & 0.186 & 0.185 & 135.08 & 8.525 & $<0.001$ \\
\hline Weekend Binary $(0,1)$ & 0.445 & 0.441 & 3103.92 & 20.352 & $<0.001$ \\
\hline Holiday Binary & 0.351 & 0.348 & 6345.14 & 16.051 & $<0.001$ \\
\hline Minir & -0.382 & -0.374 & -362.52 & -17.233 & $<0.001$ \\
\hline Precipitation Scale (0-5) & -0.253 & -0.248 & -570.15 & -11.427 & $<0.001$ \\
\hline
\end{tabular}

Each of the three models had similar explanatory power, being able to explain between 56 and 63 percent of the observed variability in daily zoo vitiation. The order of the rank of influence for each of the predictor variables remained the same between the off season and shoulder season models, with some variation in the magnitude of influence for each variable and the inclusion of the temperature threshold variable in the shoulder season. For both the off season and the shoulder season, temperature was the strongest predictor variable, followed by the social effects of weekends and then holidays, next was precipitation and then the yearly rank variable.

The peak season was certainly unique among the models with weekends having the strongest effect on visitation, followed by the negative effect of temperature, then the effect of holidays, followed by the negative effect of precipitation and then the yearly rank variable. It is also worth noting that both precipitation and the yearly rank variables had the strongest effect on visitation during the peak season, compared to the off and shoulder seasons. Furthermore, although the coefficient of determination $\left(\mathrm{R}^{2}\right)$ was lowest during the peak season; this model also had the fewest data points available for inclusion. Therefore, the slightly lower $\mathrm{R}^{2}$ value for the peak season model, compared to the other two models, is not necessarily indicative of decreased weather sensitivity, but is more likely due to the diminished statistical power of the sample size. Each of the predictor variables included in 
all three models were found to be statistically significant, with very low $\mathrm{P}$ values and excellent partial correlations, not much lower than the recoded Beta values themselves. Finally, there was no evidence of serial correlation within the data for any of the models, as evidenced by the related Durban-Watson tests, since none of the $\mathrm{d}$ values were greater than two (negative serial correlation) nor were they less than one (positive serial correlation).

\section{Ranking and Selecting Global Climate Models}

Climate models have improved since the IPCC's 2007 Forth Assessment Report (AR4). The IPCC's 2013 Fifth Assessment Report (AR5) models reproduce observed continental-scale surface temperature patterns and trends over many decades, including the more rapid warming since the mid-20th century and the cooling immediately following large volcanic eruptions. According to the IPCC (2013), the scientific community has defined a set of four new scenarios for the AR5, denoted Representative Concentration Pathways (RCPs). They are identified by their approximate total radiative forcing in year 2100 relative to $1750: 2.6 \mathrm{~W} \mathrm{~m}^{-2}$ for RCP $2.6,4.5 \mathrm{~W} \mathrm{~m}^{-2}$ for RCP 4.5, $6.0 \mathrm{~W} \mathrm{~m}^{-2}$ for RCP 6.0 , and $8.5 \mathrm{~W} \mathrm{~m}^{-2}$ for RCP 8.5. As described by the IPCC (2013), these four RCPs include one mitigation scenario leading to a very low forcing level (RCP 2.6), two stabilization scenarios (RCP 4.5 and RCP 6), and one scenario with very high GHG emissions (RCP 8.5). It is explained by the IPCC (2013) that the RCPs represent a range of $21^{\text {st }}$ century climate policies, compared with the no-climate policy approach of the Special Report on Emissions Scenarios used in the IPCC's 2001 Third Assessment Report (TAR) and 2007 AR4.

Global Climate Model output from the IPCC's 2013 AR5 can be obtained from the Coupled Model Intercomparison Project of the World Climate Research Programme. However, there is a wide selection of global climate models available to provide projections of future climate change, forty in total from the most recent assessment. Furthermore, each of the forty modelling centres provide future projections for a number of the four different RCPs, which describe how GHG concentrations could evolve over the next 100 years and thereby influence global climate. There are many approaches that have been developed in order to provide some direction for determining which of the future projections of climate available for impact assessments should be used in planning (Fenech et al., 2007). Compared against historical observed gridded data, climate projections using the ensemble approach have been shown to come closest to replicating the historical climate (IPCC, 2010). This approach suggests that it is best to plan for the average climate change from all the climate model projections by using a mean of all the models to reduce the uncertainty associated with any individual model. In effect, the individual model biases seem to offset one another when considered together. It is generally accepted that climate models can be evaluated based on their ability to reproduce baseline conditions (IPCC, 2013). Some climate models perform better in certain regions than they do in others. For this reason, it seems unreasonable to create a "full" ensemble including all of the available GCMs when it is evident that some models are unable to reproduce past climate for the study region. Based on this logic, it would seem more appropriate to evaluate each model individually, based on its ability to reproduce past climate, and then rank and select the best three models to create a "selective" ensemble from these top performing models. Tables 2 and 3 present the resulting models identified from this Selective Ensemble Approach, as well as the statistics required to formulate the ranking, referred to as the Gough-Fenech confidence index (GFCI) (Fenech, 2009).

Table 2. Selected seasonal global climate models for precipitation (GCM output from the IPCC's 2013 AR5 for precipitation at Richmond Hill based on the 1981 to 2010 baseline)

\begin{tabular}{|c|c|c|c|c|c|}
\hline \multicolumn{2}{|c|}{ Season Model - Experiment } & \multicolumn{4}{|c|}{ OBS Mean OBS StDev MOD Mean GFCI Score } \\
\hline \multirow{6}{*}{ 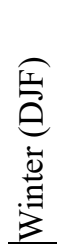 } & CESM1-CAM5 (Mean) RCP2.6 & 2.132 & 4.387 & 2.120 & 0.003 \\
\hline & CESM1-CAM5 (Mean) RCP8.5 & 2.132 & 4.387 & 2.072 & 0.014 \\
\hline & FGOALS-g2 (Run 1) RCP2.6 & 2.132 & 4.387 & 2.173 & 0.009 \\
\hline & FGOALS-g2 (Run 1) RCP8.5 & 2.132 & 4.387 & 2.209 & 0.018 \\
\hline & GISS-E2-R (Run 1) RCP2.6 & 2.132 & 4.387 & 2.082 & 0.011 \\
\hline & GISS-E2-R (Run 1) RCP8.5 & 2.132 & 4.387 & 2.083 & 0.011 \\
\hline \multirow{6}{*}{ 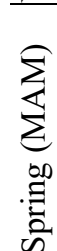 } & IPSL-CM5A-MR(Run 1) RCP2.6 & 2.286 & 5.076 & 2.138 & 0.029 \\
\hline & IPSL-CM5A-MR(Run 1) RCP8.5 & 2.286 & 5.076 & 2.190 & 0.019 \\
\hline & MIROC5(Mean) RCP2.6 & 2.286 & 5.076 & 2.320 & 0.007 \\
\hline & MIROC5(Mean) RCP8.5 & 2.286 & 5.076 & 2.367 & 0.016 \\
\hline & NorESM1-ME(Run 1) RCP2.6 & 2.286 & 5.076 & 2.317 & 0.006 \\
\hline & NorESM1-ME(Run 1) RCP8.5 & 2.286 & 5.076 & 2.327 & 0.008 \\
\hline
\end{tabular}




\begin{tabular}{|c|c|c|c|c|c|}
\hline \multirow{6}{*}{ 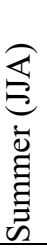 } & bcc-csm1-1(Run 1) RCP2.6 & 2.788 & 7.263 & 2.683 & 0.014 \\
\hline & bcc-csm1-1(Run 1) RCP8.5 & 2.788 & 7.263 & 2.807 & 0.003 \\
\hline & BNU-ESM(Run 1) RCP2.6 & 2.788 & 7.263 & 2.889 & 0.014 \\
\hline & BNU-ESM(Run 1) RCP8.5 & 2.788 & 7.263 & 2.933 & 0.020 \\
\hline & FGOALS-g2(Run 1) RCP2.6 & 2.788 & 7.263 & 2.716 & 0.010 \\
\hline & FGOALS-g2(Run 1) RCP8.5 & 2.788 & 7.263 & 2.687 & 0.014 \\
\hline \multirow{6}{*}{ 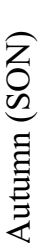 } & BNU-ESM(Run 1) RCP2.6 & 2.652 & 6.162 & 2.644 & 0.001 \\
\hline & BNU-ESM(Run 1) RCP8.5 & 2.652 & 6.162 & 2.632 & 0.003 \\
\hline & HadGEM2-AO(Run 1) RCP2.6 & 2.652 & 6.162 & 2.681 & 0.005 \\
\hline & HadGEM2-AO(Run 1) RCP8.5 & 2.652 & 6.162 & 2.718 & 0.011 \\
\hline & MPI-ESM-MR(Run 1) RCP2.6 & 2.652 & 6.162 & 2.707 & 0.009 \\
\hline & MPI-ESM-MR(Run 1) RCP8.5 & 2.652 & 6.162 & 2.623 & 0.005 \\
\hline
\end{tabular}

Table 3. Selected seasonal global climate models for temperature (GCM output from the IPCC's 2013 AR5 for temperature at Richmond Hill based on the 1981 to 2010 baseline)

\begin{tabular}{|c|c|c|c|c|c|}
\hline \multicolumn{2}{|c|}{ Season Model - Experiment } & \multicolumn{4}{|c|}{ OBS Mean OBS StDev MOD Mean GFCI Score } \\
\hline \multirow{6}{*}{ 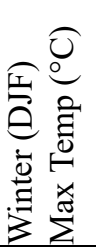 } & FIO-ESM (Mean) RCP2.6 & -0.744 & 5.601 & -0.679 & 0.012 \\
\hline & FIO-ESM (Mean) RCP8.5 & -0.744 & 5.601 & -0.568 & 0.031 \\
\hline & GFDL-CM3 (Run 1) RCP2.6 & -0.744 & 5.601 & -0.667 & 0.014 \\
\hline & GFDL-CM3 (Run 1) RCP8.5 & -0.744 & 5.601 & -0.514 & 0.041 \\
\hline & MIROC-ESM-CHEM (Run 1) RCP2.6 & -0.744 & 5.601 & -0.584 & 0.029 \\
\hline & MIROC-ESM-CHEM (Run 1) RCP8.5 & -0.744 & 5.601 & -0.643 & 0.018 \\
\hline \multirow{6}{*}{$\begin{array}{l}\sum_{0}^{0} \\
\sum_{0}^{0} \\
0 \\
0 \\
0 \\
0 \\
0 \\
0 \\
0 \\
0\end{array}$} & bcc-csm1-1-m (Run 1) RCP2.6 & 11.953 & 8.562 & 11.708 & 0.029 \\
\hline & bcc-csm1-1-m (Run 1) RCP8.5 & 11.953 & 8.562 & 11.924 & 0.003 \\
\hline & GISS-E2-H (Run 1) RCP2.6 & 11.953 & 8.562 & 11.857 & 0.011 \\
\hline & GISS-E2-H (Run 1) RCP8.5 & 11.953 & 8.562 & 11.795 & 0.018 \\
\hline & HadGEM2-ES (Mean) RCP2.6 & 11.953 & 8.562 & 12.065 & 0.013 \\
\hline & HadGEM2-ES (Mean) RCP8.5 & 11.953 & 8.562 & 11.977 & 0.003 \\
\hline \multirow{6}{*}{ 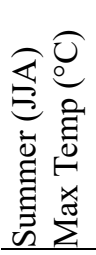 } & CSIRO-Mk3-6-0 (Mean) RCP2.6 & 25.599 & 4.111 & 25.770 & 0.042 \\
\hline & CSIRO-Mk3-6-0 (Mean) RCP8.5 & 25.599 & 4.111 & 25.795 & 0.048 \\
\hline & HadGEM2-ES (Mean) RCP2.6 & $25.5 \mathrm{c}$ & 4.111 & 25.677 & 0.019 \\
\hline & HadGEM2-ES (Mean) RCP8.5 & 25.599 & 4.111 & 25.620 & 0.005 \\
\hline & IPSL-CM5A-MR (Run 1) RCP2.6 & 25.599 & 4.111 & 25.476 & 0.030 \\
\hline & IPSL-CM5A-MR (Run 1) RCP8.5 & 25.599 & 4.111 & 25.487 & 0.027 \\
\hline \multirow{6}{*}{ 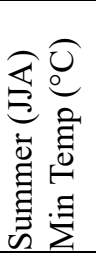 } & bcc-csm1-1-m (Run 1) RCP2.6 & 14.743 & 3.715 & 14.518 & 0.061 \\
\hline & bcc-csm1-1-m (Run 1) RCP8.5 & 14.743 & 3.715 & 14.312 & 0.116 \\
\hline & CCSM4 (Mean) RCP2.6 & 14.743 & 3.715 & 15.079 & 0.091 \\
\hline & CCSM4 (Mean) RCP8.5 & 14.743 & 3.715 & 15.068 & 0.087 \\
\hline & GFDL-CM3 (Run 1) RCP2.6 & 14.743 & 3.715 & 15.037 & 0.079 \\
\hline & GFDL-CM3 (Run 1) RCP8.5 & 14.743 & 3.715 & 15.079 & 0.090 \\
\hline \multirow{6}{*}{ 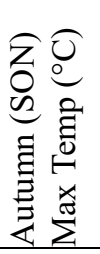 } & bcc-csm1-1-m (Run 1) RCP2.6 & 13.935 & 7.646 & 14.164 & 0.030 \\
\hline & bcc-csm1-1-m (Run 1) RCP8.5 & 13.935 & 7.646 & 14.129 & 0.025 \\
\hline & HadGEM2-AO (Run 1) RCP2.6 & 13.935 & 7.646 & 13.784 & 0.020 \\
\hline & HadGEM2-AO (Run 1) RCP8.5 & 13.935 & 7.646 & 13.871 & 0.008 \\
\hline & MIROC-ESM (Run 1) RCP2.6 & 13.935 & 7.646 & 13.746 & 0.025 \\
\hline & MIROC-ESM (Run 1) RCP8.5 & 13.935 & 7.646 & 13.797 & 0.018 \\
\hline
\end{tabular}

Of the forty different GCMs available from the IPCC's 2013 AR5, only those with projections for RCP 2.6 and RCP 8.5 when considerable for inclusion within this selective ensemble approach. Previously, researchers in field of climate change and tourism had advocated for selecting models in an effort to capture the full range of model uncertainty by selecting the models whose projections were positioned on the outer-limits of a scatterplot (Jones \& Scott, 2006a, 2006b; Scott \& Jones, 2006, 2007; Scott et al. 2003, 2006, 2007a). However, this approach does not consider model accuracy and may actually result in the selection of models that cannot reproduce past climate for the study region. Nonetheless, recognising the merit of capturing a full range of uncertainty (in regard to future global emissions, GHG concentrations and subsequent radiative forcing), 
projections were based on the least (2.6) and greatest (8.5) change RCPs, while still employing the selective ensemble approach to improve climate model accuracy. The GFCI (Fenech, 2009) was employed to evaluate the ability of the available AR5 GCMs to reproduce past climate conditions for temperature and precipitation in each of the four different seasons. This approach takes the absolute value of the observed average baseline condition (either temperature or precipitation), subtracted by the modelled average baseline condition, and then divided by the standard deviation of the observed baseline conditions. From this process, a GFCI score was calculated for each model and for each RCP followed by that model. The closer to 0 that the GFCI score was, the better the model was able to reproduce past climate, and therefore a greater likelihood of generating more accurate climate change projections. The top three models were selected based on the combined GFCI score for the two different RCPs.

\section{Downscaling Global Climate Model Output}

Not only is GCM output coarse in relation to its spatial scale, representing a general region and not a particular location; it is also coarse in relation to its temporal scale, typically conveying only monthly change and not able to produce daily climate change scenarios (Pielke \& Wilby, 2012). For these reasons, the GCM output generated through the selective ensemble approach (Table 4) was used to guide the production of local point, daily climate change scenarios in the Statistical Down-Scaling Model (SDSM) Version 5.2. This software is a stochastic weather generator but also uses data from the National Centers for Environmental Prediction and the National Center for Atmospheric Research, which represents the state of the Earth's atmosphere during the baseline period, to identify the strongest atmospheric predictor variables and thereby create models more capable of generating synthetic weather data that is able to reproduce past climate for a particular location (Wilby et al. 2001). The SDSM process involves an initial data quality control stage; then the evaluation and selection of atmospheric predictor variables; then a model calibration step; followed by a historical weather generation stage; then a model validation process is completed by comparing observed and modelled baseline conditions; finally, future climate change scenarios are generated, guided by the GCM output from the selective ensemble approach. This decision-making tool has been widely applied within the field of applied climatology and for climate change impact assessments (Wilby \& Dawson, 2012).

Table 4. Seasonal climate change projections for Richmond Hill.

\begin{tabular}{llll}
\hline Season & 2020s (2011-2040) & 2050s (2041-2070) & 2080s (2071-2100 \\
\hline \multicolumn{2}{l}{ Temperature Change in Degrees Celsius for Daily Maximum (Daily } & Minimum during Summer) \\
Winter (JFD) & 1.5 to 1.7 & 2.0 to 3.5 & 2.0 to 5.8 \\
Spring (MAM) & 1.3 to 1.4 & 1.6 to 3.1 & 1.4 to 4.6 \\
Summer (JJA) & 1.4 to $1.5(1.2$ to 1.6$)$ & 2.1 to $3.8(1.7$ to 3.5$)$ & 2.1 to $6.9(1.8$ to 5.3$)$ \\
Fall (SON) & 1.3 to 1.7 & 2.3 to 3.7 & 2.4 to 6.4 \\
\hline Precipitation Change in Percentage for Total $\mathbf{m m}$ /Day & \\
Winter (JFD) & 1.3 to 6.3 & 0.5 to 18.5 & 8.7 to 26.4 \\
Spring (MAM) & 5.4 to 6.6 & 7.2 to 17.1 & 12.9 to 15.8 \\
Summer (JJA) & -1.2 to -2.9 & 6.1 to -4.9 & 2.7 to -4.0 \\
Fall (SON) & -5.7 to -1.2 & 1.5 to 3.0 & -3.0 to -3.7
\end{tabular}

Note. Temperature and precipitation change based on a selective ensemble of GCM outputs from the IPCC's 2013 AR5, showing the upper and lower bounds of the available RCPs (2.6 and 8.5).

\section{Validating the Predictive Models}

Before using the predictive weather-visitation models in combination with the daily climate change scenarios to assess the impact on future zoo visitation, it is important to validate the predictive capacity of these models. There is a convenient overlap between the observational zoo visitation record and the modelled baseline climate conditions defined as the period from 1999-2010 (12 years). This period serves as a useful validation tool, a revealing aspect of any modelling study, not often present in tourism climate change impact assessments. Using the synthetic daily weather data generated in SDSM from 1999 to 2010 (taken from the larger data set that covered 1981 to 2010), it was possible to model visitation for these same 12 years using the regression equations that define the weather-visitation models described earlier. The regression equations for each of the seasonal weather-visitation models are as follows:

Off Season Visitation $=\operatorname{EXP}(5.552+0.024 *$ Year $+0.995 *$ Weekend $+1.691 *$ Holiday $+0.081 *$ Tmax 


\section{$-0.168 *$ Precip $) * \operatorname{EXP}(0.5 *$ POWER $(0.654,2))$ \\ Shoulder Season Visitation $=E X P(6.141+0.010 *$ Year $+1.005 *$ Weekend +1.665 \\ *Holiday $+0.082 *$ Tmax $-0.379 *$ TooHot $-0.130 *$ Precip $) * \operatorname{EXP}(0.5 *$ POWER $(0.623,2))$ \\ Peak Season Visitation $=$ \\ 11259.01+135.08*Year $+3103.92 *$ Weekend $+6345.14 *$ Holiday-362.52*Tmin-570.15* Precip}

Figure 4 illustrates the ability of the predictive models to reproduce the annual trend in zoo visitation from 1999 to 2010. By comparing the slope of the linear trend for total annual zoo visitation from both the observed and modelled data, it is apparent that the predictive models were able to reproduce the magnitude and direction of change in zoo visitation over the validation period. Given the fact that the three models combined were only able to explain an average of $60 \%$ of the observed variation in zoo visitation, the two lines are not identical. Zoo visitation increased by an average of 26,000 visitors per year based on the slope of observed linear trend line; however, the modelled record underestimates the rate of increase in zoo visitation, suggesting an increase of only 20,500 visitors each year. Furthermore, the models were not able to fully capture certain annual extremes; such as the visitation low in 2003 or the two spikes in visitation during 2007 and 2009. The conservative nature of the predictive models, as well as their inability to fully capture extremes, is likely explained by other socio-economic variables not included in the model. These sorts of variables cannot be controlled for within the future scenarios (i.e. fuel prices, exchanges rates, disposable income, special attractions), and therefore must be held constant. This issue has been recognised as a limitation to the modelling approach for tourism-based climate change impact assessments (Rosselló-Nadal, 2014). The validation process not only helps identify the limitations of this modelling approach, it also provides assurance in regard to the accuracy of the results, especially in relation to the magnitude and direction of change associated with total annual zoo visitation under projected climate change.

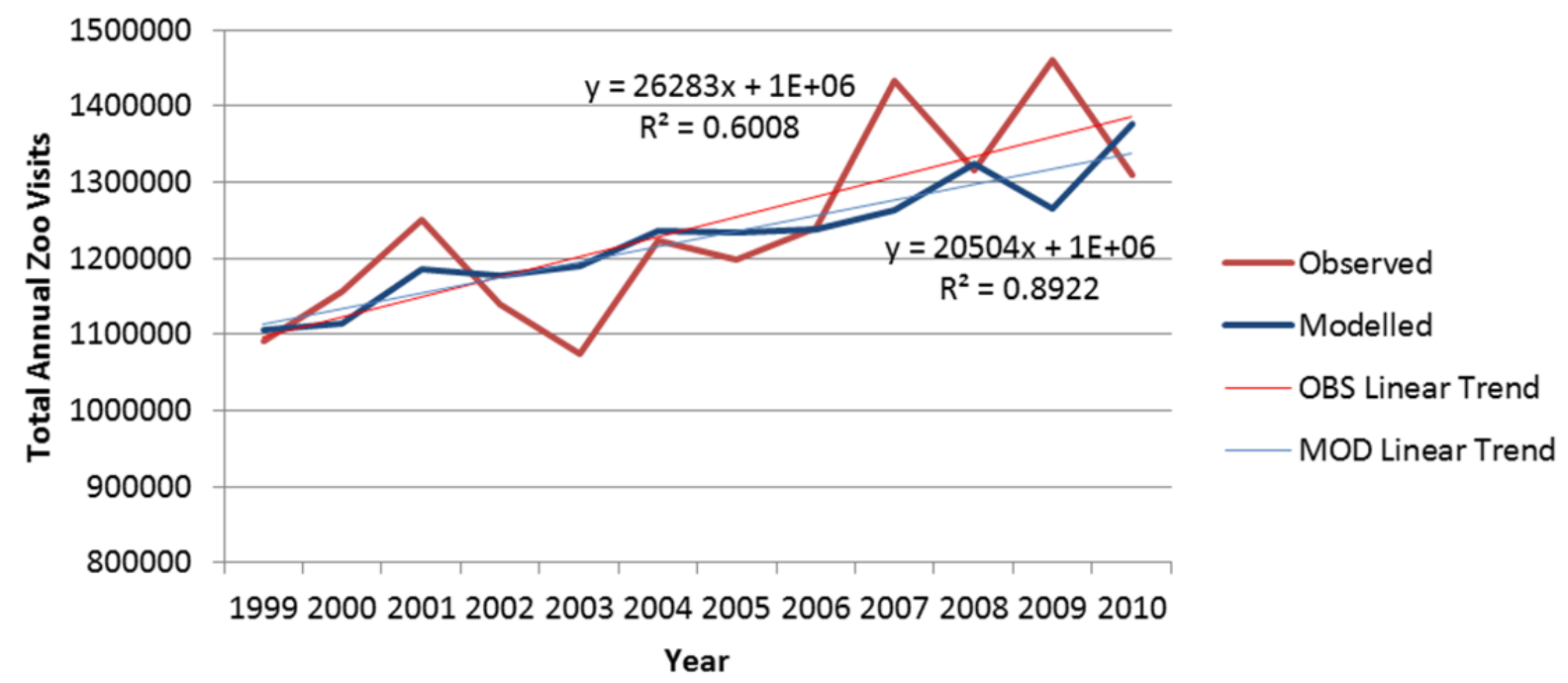

Figure 4. Comparison of observed and modelled total annual zoo visitation from 1999 to 2010 (Linear trend lines have been plotted, including the slope of the line and the co-efficient of determination, describing the strength and direction of the statistical relationship between visitation and time)

Figure 5 illustrates the ability of the predictive models to reproduce patterns of seasonality in zoo visitation over the 12 year validation period from 1999 to 2010 . The three seasonal weather-visitation models were able to reproduce patterns of seasonality with greater accuracy than they could reproduce total annual zoo visitation. For 8 out of the 12 months, the plots for average monthly zoo visitation between the observed and modelled data were quite similar. However, the model had difficulty reproducing visitation in the months of May and June as well as September and October. In May and June the model underestimated zoo visitation; whereas, in the September and October the model overestimated zoo visitation. All four of these months were contained within the shoulder season model. Interestingly, there seems to be somewhat of an offsetting effect when considering the overall effect within the model as well as the annual impact since there were two months with lower visitation and two months with higher visitation. Local climate is quite similar when comparing May and June with September and October; however, visitation differs considerably. These monthly discrepancies between 
modelled and observed visitation is likely due to factors associated with institutional seasonality (Butler, 1998). Although climate conditions are similar either side of the peak season (July \& August), zoo visitation seems to be ramping up through the spring (May \& June), but then drops sharply in the fall (September \& October). Apparently, the models were not able to capture the effects of these socio-cultural factors associated with zoo visitor behaviour (which may be explained by the typical timing of organized school trips to the zoo, which generally tend to be more common in the spring than the fall). However, overall, the predictive models did an excellent job reproducing patterns of seasonality accosted with zoo visitation.

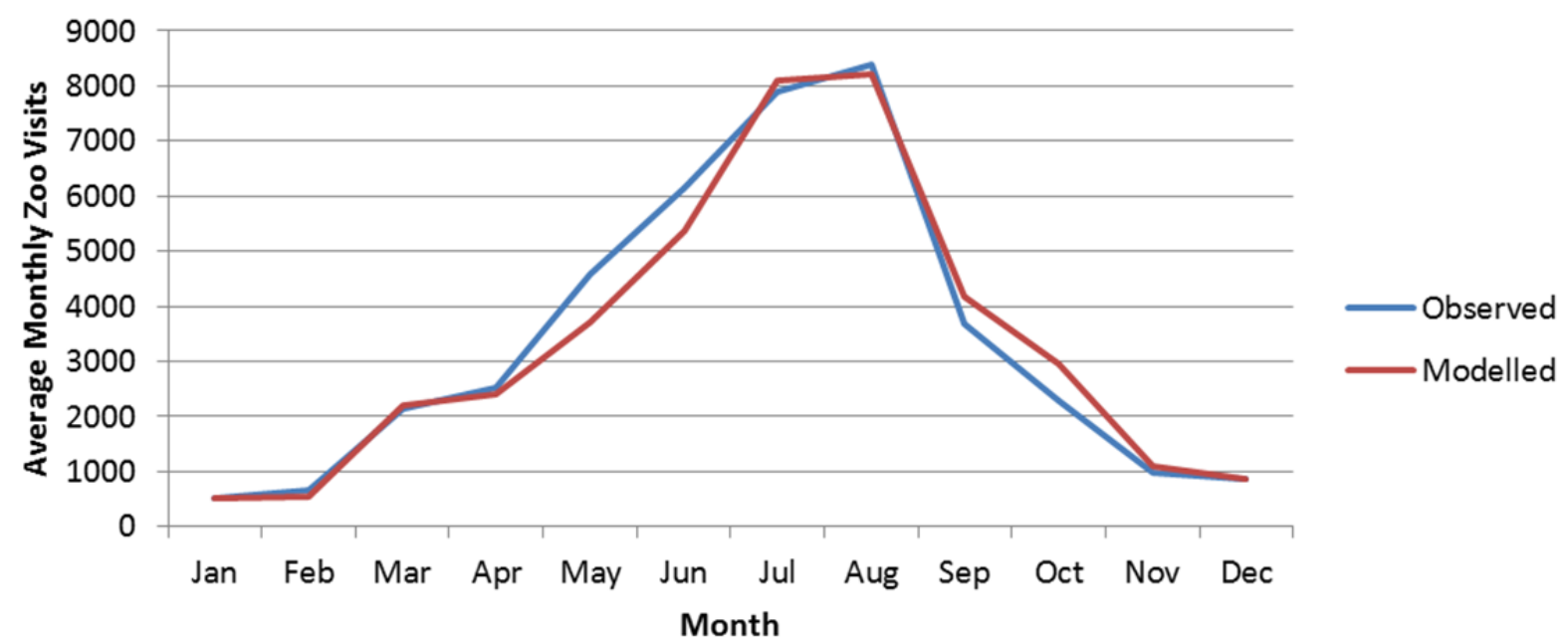

Figure 5. Comparison of observed and modelled patterns of seasonality for zoo visitation (The average number of observed and modelled visitors for 1999 to 2010 plotted for each month)

\section{Climate Change Impact Assessment}

The seasonal weather-visitation multivariate regression models were used to predict future daily zoo visitation for the remainder of the $21^{\text {st }}$ century. The predictive models were applied to the daily climate change scenarios generated in SDSM, which were guided by GCM outputs taken from the IPCC's 2013 AR5, using the selective ensemble approach. Table 5 displays the magnitude and direction of change associated with the different predictor variables included in the models, as well as the impact on the exposure unit. Although the GCM output was extracted for each climatic season (winter, spring, summer, fall), and zoo visitation was modelled separately for the three different visitation seasons (off, shoulder, peak). The projected changes are summarised based on their annual effects over the three different change periods: the 2020s (2011-2040), the 2050s (2041-2070), and the 2080s (2071-2100).

Table 5. Projected climatic changes and modelled impact on zoo visitation.

\begin{tabular}{lrrr}
\hline Variable & $\Delta(\mathbf{2 0 2 0 s})$ & $\Delta(\mathbf{2 0 5 0 s})$ & $\Delta(\mathbf{2 0 8 0 s})$ \\
\hline Average Annual Maximum Temperature & 1.4 to $1.6^{\circ} \mathrm{C}$ & 2.0 to $3.5^{\circ} \mathrm{C}$ & 2.0 to $5.9^{\circ} \mathrm{C}$ \\
Average Annual Number of Days Exceeding $26^{\circ} \mathrm{C}$ & 17 to 19 days & 26 to 44 days & 26 to 70 days \\
Average Annual Minimum Temperature & 1.2 to $1.6^{\circ} \mathrm{C}$ & 1.7 to $3.5^{\circ} \mathrm{C}$ & 1.8 to $5.3{ }^{\circ} \mathrm{C}$ \\
Total Annual Precipitation & -3.0 to $-1.3 \%$ & 1.7 to $10.9 \%$ & 5.5 to $18.3 \%$ \\
Total Annual Zoo Visits & 7.6 to $7.8 \%$ & 14.0 to $17.3 \%$ & 18.3 to $33.9 \%$ \\
\hline
\end{tabular}

Note. Climatic change based on SDSM scenarios for Richmond Hill from 2011 to 2100, guided by GCM output (RCP 2.6 to RCP 8.5), selected using the GFCI. Potential impact on visitation to the Toronto Zoo based on predictions from the seasonal weather-visitation multivariate regression models.

The yearly rank variable, whose effect was derived from the increasing trend in annual visitation from 1999-2013, was manipulated in the modelled projections so that each decade represented a year. This was done because it was thought to be unreasonable that visitation would continue to increase at an average rate of 20,000 visitors each year, over the next 90 years; so instead, that rate of increase would only be realised nine times. This 
was done in an effort to control for limits to population growth and zoo expansion expected to be realised as the $21^{\text {st }}$ century unfolds; while also making the future projections more realistic and further isolating the effect of projected climate change. Based on the daily climate change scenarios, Tmax was projected to increase from +1.4 to $+5.9{ }^{\circ} \mathrm{C}$ over the course of the 21 st century; whereas, Tmin was projected to increase from +1.2 to $+5.3{ }^{\circ} \mathrm{C}$. The total number of days when Tmax exceeded $26{ }^{\circ} \mathrm{C}$ (not including the peak months of July and August) was projected to increase from 17 to 70 days over the course of the 21 st century. Changes in precipitation for the region under projected climate change vary more drastically by season and follow a different pattern than temperature. In the $2020 \mathrm{~s}$, precipitation may decrease by -1.3 to -3.0 percent; whereas, from the $2050 \mathrm{~s}$ and on to the end of the century, precipitation may increase from +1.7 to +18.3 percent. The social variables associated with the effect of weekends and holidays remained constant throughout the modelled projections. Under the low emission, low radiative forcing RCP (2.6), annual visitation was projected to increase from +7.6 to +18.3 percent over the course of the $21^{\text {st }}$ century. Whereas, under the high emission, high radiative forcing RCP (8.5); annual visitation was projected to increase from +7.8 to +33.9 percent.

Figure 6 illustrates the projected rate of increase in total annual zoo visitation for the $21^{\text {st }}$ century under both the selected RCPs. Under the RCP 2.6 climate change scenario, as indicated by the slope of the linear trend line, total annual zoo visitation is projected to increase by approximately 2000 visits each year over the course the $21^{\text {st }}$ century; resulting in approximately 200,000 additional annual visitors by the year 2100 . Under RCP 2.6 , projected climate change is minimal (unlikely to exceed a $2{ }^{\circ} \mathrm{C}$ warming by the end of the century). Therefore, much of the modelled increase in zoo visitation is likely due to continued trends associated with population growth and zoo expansion. Recall that the yearly rank variable derived from the increasing trend in zoo vitiation overtime observed within the observational data, although scaled back for use within the predictive models to account for limits to growth, would likely result in an additional 20,000 annual zoo visitors each decade. Under RCP 8.5 , total annual zoo visitation is projected to increase by approximately 4600 visits each year over the course the $21^{\text {st }}$ century; resulting in approximately 400,000 additional annual visitors by the year 2100 . Furthermore, the projected impact of climate change on zoo visitation does not vary much between the two RCPs in the 2020s. Whereas, in the 2050s, the impact of projected climate change on annual zoo visitation under RCP 8.5 is noticeably greater than that of RCP 2.6. However, the magnitude of difference in projected impacts between the two RCPs is greatest in the 2080s, where the impact under RCP $8.5(+33.9 \%)$ is nearly twice that of RCP $2.6(+18.3 \%)$.

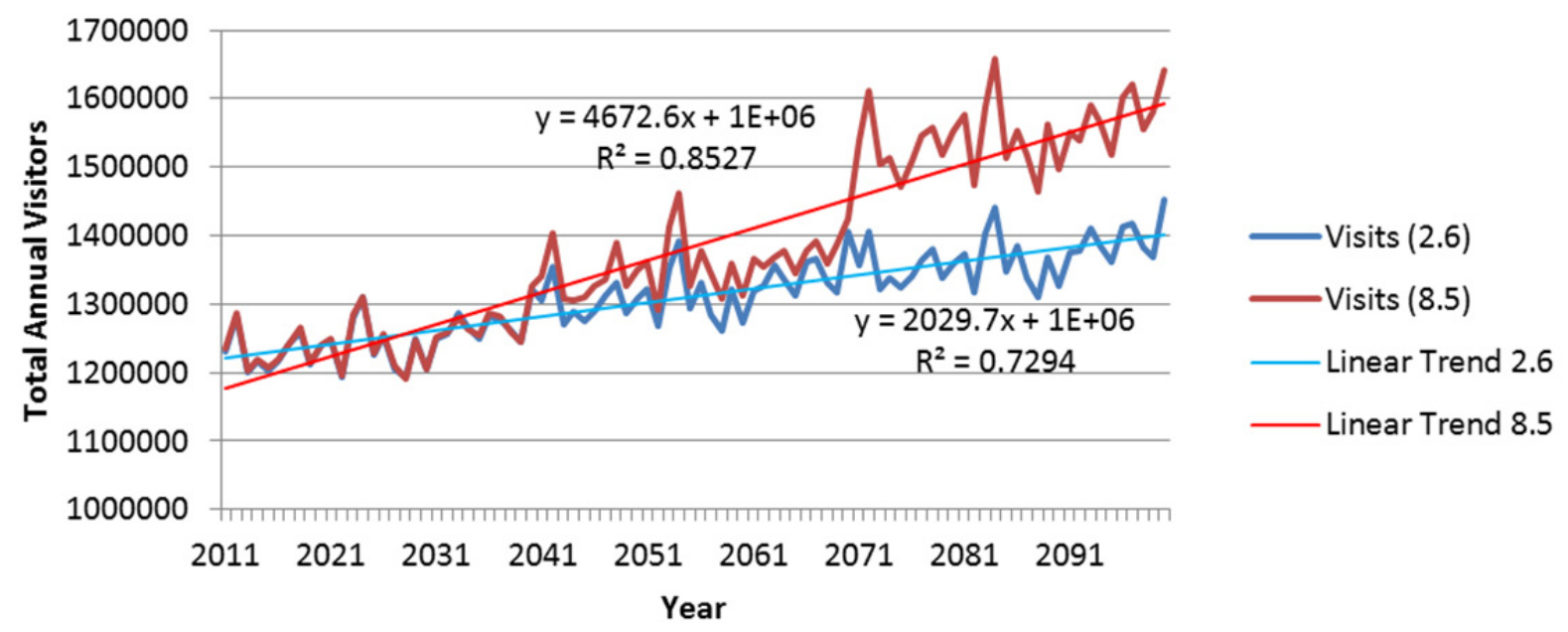

Figure 6. Annual trend in total zoo visitation under projected climate change (Projected total annual zoo plotted across the course of the 21st century for both RCP 2.6 and RCP 8.5 guided climate change scenarios. Linear trend lines have also been plotted, including the slope of the line and the co-efficient of determination, describing the strength and direction of the statistical relationship between predicted visitation and time)

Figure 7 illustrates the impact of projected climate change on the seasonality of visitation to the Toronto Zoo over the course of the 21 st century under both RCPs, by graphing monthly averages of total daily visitors for the baseline period (1981-2010) and then for the three future periods: 2020s, 2050s and 2080s. Under RCP 2.6, the model suggests that the patterns of seasonality will remain the same for zoo visitation in Toronto, with visitation expected to increase in each month over the course of the 21 st century, but with some months expected to 
experience greater increases in visitation than others. For example, the summer months are expected to experience greater increases in visitation compared to the winter months, due to the impact of projected climate change under RCP 2.6. However, under RCP 8.5 the patterns of seasonality for zoo visitation in Toronto become reshaped due to the impact of projected climate change. This discrepancy between the impacts of the two RCPs is due mainly to the way visitation responds to projected climate change in the months of July and August. Under RCP 8.5, visitation in July and August declines continually throughout the course of the 21 st century, as temperatures continue to warm. The other months are still expected to experience increases in visitation as was seen under RCP 2.6, only to a greater degree. Therefore, as visitation in the shoulder season increases and visitation in the peak season declines, the seasonal patterns of visitation become more rounded and the sharp rise and fall historically associated with the spring and fall seasons are no longer apparent by the end of the 21st century. In the 2080s, November seems to behave more like one of the shoulder season months and may no longer be considered part of the off season; meanwhile as early as the 2050s, June seems to reach peak season levels of visitation.

\section{RCP 8.5}

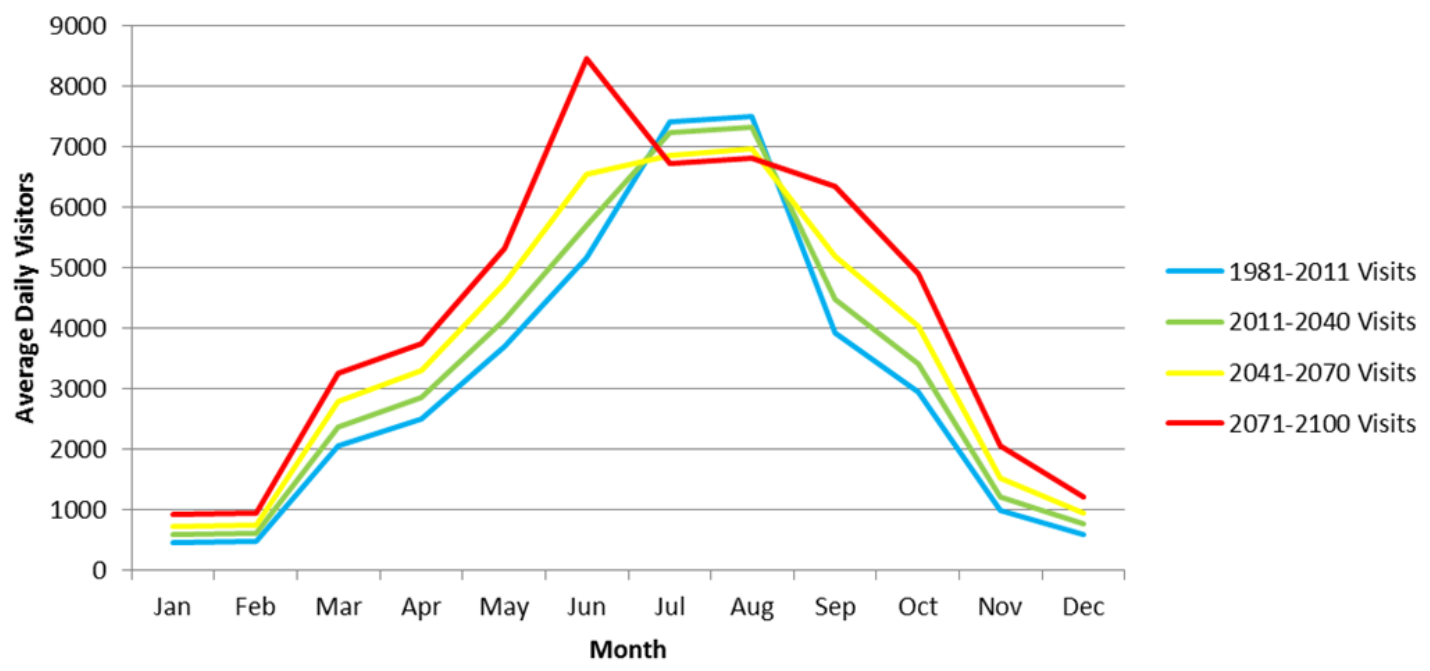

RCP 2.6

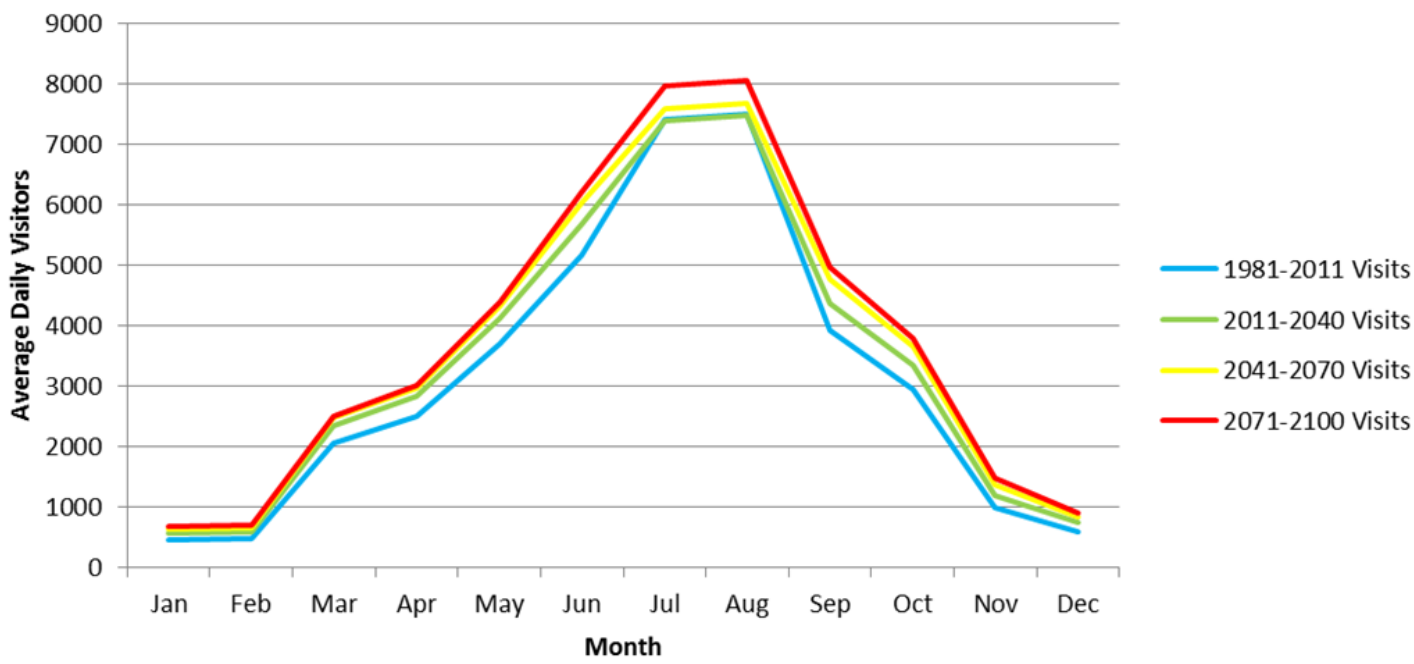

Figure 7. Patterns of seasonality for visitation to the Toronto Zoo under projected climate change (Average visitors for each month have been recorded, plotting the baseline period (1981-2010) and each change period (2020s, 2050s, 2080s), including a graph for both RCP 2.6 and RCP 8.5 climate change scenarios)

There is a clear anomaly associated with the modelled projections under RCP 8.5 in the 2080s for the month of June. The model suggests an unlikely spike in visitation. It is more likely that by the end of the $21^{\text {st }}$ century, 
visitation in June will be similar to visitation in July and August, and therefore to be modelled correctly would require the use of the peak season model parameters rather than those of the shoulder season model. Recall that the difference between these two models was that the in the shoulder season the strongest predictor of visitation was the positive effect of Tmax; whereas, in the peak season the strongest climatic predictor was the negative effect of Tmin.

\section{Discussion and Conclusions}

This study conducted a formal climate change impact assessment on visitation to the Toronto Zoo in Ontario, Canada. Multivariate regression was employed to determine the statistical relationship between weather and visitation within the study region, from which predictive models were developed. The GFCI (Fenech, 2009) was used to rank and select a number of top performing GCMs, evaluated based on their ability to reproduce past climate within the region, from which a "selective" ensemble of future climatic change projections was created. This information was then used to generate downscaled, local-point, daily climate change scenarios in SDSM 5.2. Predicted visitation from the models was then validated against observational data, using the synthetic weather generated in SDSM for the period from 1999 to 2010. Satisfied with the validation process, the seasonal weather-visitation models were then employed to assess the potential impact of projected climate change on zoo visitation over the course of the $21^{\text {st }}$ century, based on full range of uncertainty pertaining to future global emissions, GHG concentration and subsequent radiative forcing (RCP 2.6 to RCP 8.5).

The results of this study illustrate that there has already been an observable warming trend within the region. Projected climate change is expected to accelerate that warming process. The regression analysis revealed that daily zoo visitation is highly correlated with weather variability. On average, the seasonal models were able to explain $60 \%$ of the observed variability in daily zoo vitiation; with temperature found to be the strongest predictor variable in two out of the three seasonal models. Under a hypothetic global emissions mitigation strategy (RCP 2.6), resulting in lower radiative forcing and subsequent climatic changes, it is projected that the effect of moderate warming over the course of the $21^{\text {st }}$ century $\left(<2{ }^{\circ} \mathrm{C}\right)$ will result in increased annual zoo visitation (from $+7.6 \%$ in the 2020 s to $+18.3 \%$ in the 2080 s), without causing any significant changes to the patterns of seasonality. For RCP 8.5 , an accelerated emissions and subsequent warming scenario $\left(+3.5^{\circ} \mathrm{C}\right.$ by the $2050 \mathrm{~s}$ and $+5.9^{\circ} \mathrm{C}$ by the $2080 \mathrm{~s}$ ), annual visitation increased at a much greater rate (from $+7.8 \%$ in the $2020 \mathrm{~s}$ to $+33.9 \%$ in the $2080 \mathrm{~s}$ ), with notable shifts in the patterns of seasonality. For RCP 8.5 , by the 2050 s, there was a notable decline in peak season visitation, accompanied by increases in visitation during the shoulder season months. These changes resulting in a much more rounded pattern of seasonality, compared to the sharp rise and fall associated with visitation on either side of the peak season months of July and August under baseline climate conditions. Furthermore, by the 2080s, this shifting pattern of seasonality was even more pronounced, to such a degree that model apparently failed to predict June visitation for this time period (producing unreasonably high levels of visitation for the month). This modelling limitation was nonetheless revealing, as it suggests that as average annual temperatures exceed $3.5^{\circ} \mathrm{C}$ and continue to increase as high as $5.9^{\circ} \mathrm{C}$, visitation in June will start to behave much more like that in July and August and would therefore need to be modelled the way the peak season was in order to produce more reliable predictions.

The results of this study are contrary to the conclusions drawn by Aylen et al (2014), which were derived from their statistical analysis of the relationship between weather, climate and zoo visitation in England. Although no formal climate change impact assessment was conducted, Aylen et al. (2014) suggested that projected climate change in unlikely to have a considerable influence on the total number of visitors to Chester Zoo in England. However, it is reasonable to suggest that the weather sensitivity of zoo visitation varies based on geographic location and climatic conditions. Such disparate results between geographic locations are further emphasised in the findings that suggest zoo visitors in Toronto, Canada found temperatures over $26^{\circ} \mathrm{C}$ were too hot; whereas, Aylen et al. (2014) reported temperatures exceeding $21^{\circ} \mathrm{C}$ as being too hot for zoo visitors in Manchester, England.

A number of informed management recommendations can be suggested as an adaptation strategy from the results of this climate change impact assessment of zoo visitation in Toronto. To begin, regardless of the impact of projected climate change, the strongest relationship between visitation and weather in the peak season months of July and August was a negative correlation between Tmin and the total number of daily visitors. Therefore, uncomfortably warm temperatures during the peak season as already a deterrent to zoo visitation. Although this relationship was not expected to cause peak season visitation to decline until additional warming between 3.5 to $5.9^{\circ} \mathrm{C}$ was realised (from the mid to late $21^{\text {st }}$ century); it would be in the zoo's immediate best interest to devote further efforts towards mitigating the adverse effects of thermal stress on zoo visitors. Such strategies may include further expansion and promotion of the existing splash pad (water park), as well as increased cooling and 
hydration stations. Possibly even providing discounted cold beverages and frozen treats when temperatures are perceived by visitors as being too warm (i.e. when Tmax $>26{ }^{\circ} \mathrm{C}$ ). If the temperatures continue to increase due to the local UHI and global climate change (which is very likely), in additional to threats of declining peak season visitation, there are also opportunities for increased shoulder season visitation. Not only will the potential for increased visitation during the shoulder season months need to be planned for by zoo managers (i.e. additional staff and programmes), but should also be met with increased promotion to take full advantage of this opportunity under projected climate change.

This study was subject to a number of limitations. To begin, the relationship between weather and visitation was determined with participation data that did not reveal the varying characteristics of different zoo visitors. The question that therefore remains is how do different types of zoo visitors perceive and respond to weather (i.e. day users versus season pass holders; families versus couples; the elderly versus young adults). Some of these important questions could be answered by exploring the relationship between weather and zoo visitation using a stated climate preferences approach (Scott et al. 2008; Rutty \& Scott, 2010, 2013; Hewer et al. 2014). Furthermore, when validating the predictive models it was acknowledged that the modelled output was not able to capture a number of the annual visitation extremes, which may have been due to prevailing socio-economic conditions or climatic anomalies. In addition, the revealed weather sensitivity and temperature thresholds do not account for the adaptive capacity of tourists (Scott et al. 2012), shifting climate preferences (Gössling et al. 2012) or human acclimatization (Kajan \& Saarinen, 2013); concerns that have been raised about using the modelling approach for determining the weather sensitivity and assessing climate change impacts for tourism. This limitation may be overcome by employing a climate analogue approach to better understand how zoo visitation responds during seasons and years when climate conditions are anomalously warm or wet. The use of temporal climate analogues to enable a better understanding of the relationship between weather and tourism and to more accurately assess the impact of climate change on tourism has been strongly encouraged within some of the recent tourism-climate literature reviews (Gössling et al. 2012; Scott et al. 2012), while also being well-defined in its application to the ski industry (Steiger, 2011; Dawson et al. 2009). Nonetheless, the current study has revealed that zoo visitation in Toronto is a highly weather-sensitive tourism and recreation activity which will most likely be impacted by projected climate change, making future research in this regard an important task to enable more informed planning and management.

\section{Acknowledgements}

The authors would like to thank the Toronto Zoo for their willingness to support this research by providing the necessary daily zoo visitation data. In particular, we would like to thank the Chief Executive Officer at The Toronto Zoo for taking the time to meet with us, then agreeing to participate in the study and approving the release of the required data. The Senior Director of Marketing, Communications and Partnerships at the Toronto Zoo is also deserving of our gratitude for the time and effort spent organizing the supply and distribution of the visitation data. Furthermore, we would like to thank the former Vice-Principal of Research at the University of Toronto Scarborough for contacting the Toronto Zoo on our behalf, which was certainly instrumental in the working relationship we now have with the zoo.

\section{References}

Abegg, B., Konig, U., Burki, R., \& Elsasser, H. (1997). Climate impact assessment. Tourismus Die Erde, 128, 105- 116.

Aylen, J., Albertson, K., \& Cavan, G. (2014). The impact of weather and climate on tourism demand: the case of Chester Zoo. Climatic Change, 127, 183-197. http://dx.doi.org/10.1007\%2Fs10584-014-1261-6

Barbosa, A. (2009). The role of zoos and aquariums in research into the effects of climate change on animal health. International Zoo Yearbook, 43, 131-135. http://dx.doi.org/10.1111/j.1748-1090.2008.00073.x

Becken, S. (2013). A review of tourism and climate change as an evolving knowledge domain. Tourism Management Perspectives, 6, 53-62. http://dx.doi.org/10.1016/j.tmp.2012.11.006

Butler, R. (1998). Seasonality in tourism: Issues and implications. The Tourist Review, 53, 18-24. http://dx.doi.org/10.1108/eb058278

Canadian Tourism Commission (CTC). (2015). Tourism as Canada's engine for growth: CTC 2014 annual report. Vancouver, Canada: CTC. Retrieved http://en.destinationcanada.com/sites/default/files/pdf/Corporate_reports /2014_annual_report_en_may5.pdf

Dawson, J., Scott, D., \& McBoyle, G. (2009). Climate change analogue analysis of ski tourism in north-eastern USA. Climate Research, 39, 1-9. http://dx.doi.org/10.3354/cr00793 
de Freitas, C. (2003). Tourism climatology: evaluating environmental information for decision making and business planning in the recreation and tourism sector. International Journal of Biometeorology, 4, 45-54. http://dx.doi.org/10.1007/s00484-003-0177-z

de Freitas, C., Scott, D., \& McBoyle, B. (2008). A second generation climate index for tourism (CIT): Specification and verification. International Journal of Biometeorology, 52, 399-407. http://dx.doi.org/10.1007/s00484-007-0134-3

Fenech, A. (2009). Rapid assessment of the impacts of climate change: an integrated approach to understanding climate change in the Halton region of Ontario, Canada (Unpublished doctoral dissertation). University of Toronto, Toronto, Canada.

Fenech, A., Comer, N., \& Gough, W. (2007). Selecting a climate model for understanding future scenarios of climate change. In A. Fenech \& J. MacLellan J. (Eds) Linking Climate Models to Policy and Decision-making. Toronto, Canada: Environment Canada.

Fisichelli, N., Schuurman, G., Monahan, W., \& Ziesler, P. (2015). Protected area tourism in a changing climate: will visitation at US national parks warm up or overheat? PLOS ONE, 10(6), 1-13. http://dx.doi.org/10.1371/journal.pone.0128226

Gössling, S., Scott, D., Hall, C. M., Ceron, J. P., \& Dubois, G. (2012). Consumer behaviour and demand response of tourists to climate change. Annals of Tourism Research, 39, 36-58. http://dx.doi.org/10.1016/j.annals.2011.11.002

Gough, W. A., \& Rosanov, Y. (2001). Aspects of Toronto's climate: heat island and lake breeze. Canadian Meteorology \& Oceanography Society Bulletin, 29, 67-71.

Hewer, M., Scott, D., \& Gough, W. A. (2014). Tourism climatology for camping: a case study of two Ontario parks (Canada). Theoretical \& Applied Climatology. http://dx.doi.org/10.1007/s00704-014-1228-6

Intergovernmental Panel on Climate Change (IPCC). (2007). Climate change 2007: The physical science basis. In S. Solomon, D. Qin, M. Manning, Z. Chen, M. Marquis, K. Averyt, M. Tignor \& H. Miller (Eds.) Contribution of working group I to the fourth assessment report of the Intergovernmental Panel on Climate Change. Cambridge, UK and New York, USA: Cambridge University Press.

Intergovernmental Panel on Climate Change (IPCC). (2010). Good practice guidance paper on assessing and combining multi model climate projections. Boulder, Colorado, USA: National Center for Atmospheric Research.

Intergovernmental Panel on Climate Change (IPCC). (2013). Summary for policymakers. Climate Change 2013: The Physical Science Basis. In T. Stocker, D. Qin, G. Plattner, M. Tignor, S. Allen, J. Boschung, A. Nauels, Y. Xia, V. Bex \& P. Midgley (Eds.) Contribution of working group I to the fifth assessment report of the Intergovernmental Panel on Climate Change. Cambridge, UK and New York, USA: Cambridge University Press.

Jones, B., \& Scott, D. (2006a). Climate change, seasonality and visitation to Canada's national parks. Journal of Park \& Recreation Administration, 24, 42-62.

Jones, B., \& Scott, D. (2006b). Implications of climate change for visitation to Ontario's provincial parks. Leisure, 30, 233-261.

Junhold, J., \& Oberwemmer, F. (2011). How are the animal keeping and conservation philosophy of zoos affected by climate change? International Zoo Yearbook, 45, 99-107. http://dx.doi.org/10.1111/j.1748-1090.2010.00130.x

Kaján, E., \& Saarinen, J. (2013). Tourism, climate change and adaptation: a review. Current Issues in Tourism, 16, 167-195. http://dx.doi.org/10.1080/13683500.2013.774323

Loomis, J., \& Richardson, R. (2006). An external validity test of intended behaviour: comparing revealed preference and intended visitation in response to climate change. Journal of Environmental Planning \& Management, 49, 621-630. http://dx.doi.org/10.1080/09640560600747562

Mohsin, T., \& Gough, W.A. (2012). Characterization and estimation of urban heat island at Toronto: Impact of the choice of rural sites. Theoretical \& Applied Climatology, 108, 105-117. http://dx.doi.org/10.1007/s00704-011-0516-7

Moreno, A., \& Amelung, B. (2009). Climate change and tourist comfort on Europe's beaches in summer: A reassessment. Coastal Management, 37, 550-568. http://dx.doi.org/10.1080/08920750903054997 
Morgan, R., Gatell, E., Junyent, R., Micallef, A., Ozhan, E., \& Williams, A. (2000). An improved user-based beach climate index. Journal of Coastal Conservation, 6, 41-50. http://dx.doi.org/10.1007/BF02730466

Njoroge, J. M. (2015). Climate change and tourism adaptation: Literature review. Tourism \& Hospitality Management, 21, 95-108.

Ontario Ministry of Tourism, Culture and Sport (OMTCS). (2015). Tourism research: Quick facts 2012. Retrieved from http://www.mtc.gov.on.ca/en/research/quick_facts/facts.shtml

Pang, F., McKercher, B., \& Prideaux, B. (2013). Climate change and tourism: an overview. Asia Pacific Journal of Tourism Research, 18, 4-20. http://dx.doi.org/10.1080/10941665.2012.688509

Pearce-Kelly, P., Khela, S., Ferri, C., \& Field, D. (2013). Climate-change impact considerations for freshwater-fish conservation, with special reference to the aquarium and zoo community. International Zoo Yearbook, 47, 81-92. http://dx.doi.org/10.1111/izy.12016

Pielke, R. A., \& Wilby, R. L. (2012). Regional climate downscaling - what's the point? Eos, 93, 52-53. http://dx.doi.org/10.1029/2012EO050008

Rosselló-Nadal, J. (2014). How to evaluate the effects of climate change on tourism. Tourism Management, 42, 334-340. http://dx.doi.org/10.1016/j.tourman.2013.11.006

Rutty, M., \& Scott, D. (2010). Will the Mediterranean become "too hot" for tourism? A reassessment. Tourism \& Hospitality Planning \& Development, 7, 267-281. http://dx.doi.org/10.1080/1479053X.2010.502386

Rutty, M., \& Scott, D. (2013). Differential climate preferences of international beach tourists. Climate Research, 57, 256-269. http://dx.doi.org/10.3354/cr01183

Scott, D, Gössling, S., \& de Freitas, C. (2008). Climate preferences for tourism: Evidence from Canada, New Zealand and Sweden. Climate Research, 38, 61-73. http://dx.doi.org/10.3354/cr00774

Scott, D., \& Jones, B. (2006). The impact of climate change on golf participation in the Greater Toronto Area (GTA): A case study. Journal of Leisure Research, 38, 363-380.

Scott, D., \& Jones, B. (2007). A regional comparison of the implications of climate change on the golf industry in Canada. The Canadian Geographer, 51, 219-232. http://dx.doi.org/10.1111/j.1541-0064.2007.00175.x

Scott, D., Gössling, S., \& Hall, C. M. (2012). International tourism and climate change. WIREs Climate Change, 3, 213-232. http://dx.doi.org/10.1002/wcc. 165

Scott, D., Jones, B., \& Konopek, J. (2007). Implications of climate and environmental change for nature-based tourism in the Canadian rocky mountains: A case study of Waterton Lakes National Park. Tourism Management, 28, 570-579. http://dx.doi.org/10.1016/j.tourman.2006.04.020

Scott, D., McBoyle, G., \& Mills, B. (2003). Climate change and the skiing industry in southern Ontario (Canada): Exploring the importance of snowmaking as a technical adaptation. Climate Research, 23, 171-181. http://dx.doi.org/doi:10.3354/cr023171

Scott, D., McBoyle, G., \& Minogue, A. (2007). The implications of climate change for the Québec ski industry. Global Environmental Change, 17, 181-190. http://dx.doi.org/10.1016/j.gloenvcha.2006.05.004

Scott, D., McBoyle, G., \& Schwartzentruber, M. (2004). Climate change and distribution of climatic resources for tourism in North America. Climate Research, 27, 105-117. http://dx.doi.org/doi:10.3354/cr027105

Scott, D., McBoyle, G., Minogue, A., \& Mills, B. (2006). Change and the sustainability of ski-based tourism in eastern North America: A reassessment. Journal of Sustainable Tourism, 14, 376-398. http://dx.doi.org/10.2167/jost550.0

Steiger, R. (2011). The impact of snow scarcity on ski tourism: an analysis of the record warm season 2006/2007 in Tyrol (Austria). Tourism Review, 66, 4-13. http://dx.doi.org/10.1108/16605371111175285

Toronto Zoo. (2014). Saving and protecting species at home and abroad: Toronto Zoo annual report 2013. Toronto, Canada: Toronto Zoo. Retrieved http://www.torontozoo.com/pdfs/Toronto\%20Zoo_2013_Annual _Report.pdf

Tourism Toronto. (2014). Elevating the "new Toronto": Tourism Toronto annual report 2013. Toronto, Canada: Tourism Toronto. Retrieved http://www.seetorontonow.com/getattachment/26d64e70-372a-4282-91a115fcc0b4b7f7/AnnualReport2013_email.pdf.aspx

United Nations World Tourism Organization (UNWTO). (2015). UNWTO annual report 2014. Madrid, Spain: 
UNWTO. Retrieved http://dtxtq4w60xqpw.cloudfront.net/sites/all/files/pdf/unwto_annual_report_2014.pdf

Wilby, R. L., \& Dawson, C. W. (2012). The statistical downscaling model (SDSM): Insights from one decade of application. International Journal of Climatology, 33, 1707-1719. http://dx.doi.org/10.1002/joc.3544

Wilby, R. L., Dawson, C. W., \& Barrow, E. M. (2001). SDSM - a decision support tool for the assessment of regional climate change impacts. Environmental \& Modelling Software, 17, 145-157. http://dx.doi.org/10.1016/S1364-8152(01)00060-3

Williams, P., Dossa, K., \& Hunt, J. (1997). The influence of weather context on winter resort evaluations by visitors. Journal of Travel Research, 36, 29-36. http://dx.doi.org/10.1177/004728759703600205

Yukic, T. (1970). Fundamentals of Recreation: 2nd Edition. New York, USA: Harper \& Row; 1970.

\section{Copyrights}

Copyright for this article is retained by the author(s), with first publication rights granted to the journal.

This is an open-access article distributed under the terms and conditions of the Creative Commons Attribution license (http://creativecommons.org/licenses/by/3.0/). 